\title{
Vertical migration of the crab Carcinus maenas first zoea in an estuary: implications for tidal stream transport
}

\author{
Henrique Queiroga ${ }^{1, *}$, John D. Costlow ${ }^{2}$, Maria Helena Moreira ${ }^{1}$ \\ ${ }^{1}$ Departamento de Biologia, Universidade de Aveiro, Campus de Santiago, P-3810 Aveiro, Portugal \\ ${ }^{2}$ Duke University Marine Laboratory, Pivers Island, Beaufort, North Carolina 28516, USA
}

\begin{abstract}
The first zoea of Carcinus maenas (L.) was intensively sampled in the Canal de Mira (Ria de Aveiro, Portugal) during the winter and spring of 1990. Each sampling period included a series of $25 \mathrm{~h}$ fixed-station plankton sampling cycles (12 in winter and 9 in spring), conducted at 1 station located in the lower part of the Canal. Plankton samples were collected every hour, at several depths along the water column, with the use of a pump. Hydrological measurements (salinity, temperature and current velocity and direction) were taken immediately before the collection of the plankton samples. The average depth of the zoeae changed in phase with the tide: larvae reached their highest position in the water column during ebb and their lowest during flood. The extent and phasing of the vertical displacements were such that the first zoea occupied a significantly higher position during the span of the ebb than during flood $(p<0.001)$. It was also demonstrated that the larvae were significantly closer to the surface during the night $(p<0.05)$. The pattern of vertical dispersion of the zoeae changed cyclically, with a period equivalent to the tidal half-cycle. Maximum aggregation usually occurred during periods of high current velocity and was independent from water stratification. These observations support the hypothesis that $C$. maenas first zoea performs an actuve vertical migration synchronised with tidal and daily cycles. Analysis of the zoeae instantaneous velocity showed that shifts of vertical position according to the phases of tide and day influenced their transport velocity, due to vertical differences of water velocity in the estuarine shear current system. During ebb the larvae were transported at a velocity that exceeded the vertically integrated water velocity; the reverse relationship was observed during flood $(\mathrm{p}<0.001)$. The larvae were also transported faster during the night than during the day $(p<0.05)$. These results demonstrate that selective tidal stream transport can be generalised in the sense of a unidirectional transport mechanism in estuaries that can enhance exportation.
\end{abstract}

KEY WORDS: Carcinus maenas Larval stages Estuaries Vertical migration - Tidal stream transport Portugal

\section{INTRODUCTION}

Three different types of life cycles have evolved in species that use the estuarine environment during all or part of its cycle: (1) spawning and retention of the larvae inside the estuary; (2) spawning inside the estuary and transport of early life stages to coastal waters, followed by reinvasion of the estuary by late stage larvae or juveniles; (3) spawning in coastal waters and immigration of larvae or juveniles to the estuary, which is used as a nursery feeding ground.

\footnotetext{
•E-mail: hquerroga@bio.ua.pt
}

Planktonic larvae of these organisms typically have limited swimming capabilities (Mileikovsky 1973, Chia et al. 1984, Miller 1988): their swimming velocities are 100 to 1000 times lower than the instantaneous current velocities observed in estuaries and 10 to 100 times lower than residual (i.e. net value, disregarding the effect of the tides) velocities. In order to immigrate toor remain within - the estuarine environment, planktonic larvae need to have some kind of adaptation to oppose the net seaward flux of the waters. Selective tidal stream transport is a mechanism by which planktonic larvae and other organisms use vertical differences of water velocity in a shear current system to 
promote transport in an 'appropriate' direction. This mechanism has been proposed to explain the upstream movement of fish and invertebrate larvae against the net seaward flux of estuarine waters (Boehlert \& Mundy 1988, Epifanio 1988). Tidal currents, in estuaries or otherwise, are characterized by slower speeds close to the bottom that result from bottom friction. Under the selective tidal stream transport hypothesis the larvae remain on, or closer to, the bottom during ebb and ascend in the water column during flood. A growing body of observations suggests that these vertical displacements involve oriented movements by the larvae and are thus under behavioural control (Cronin \& Forward 1979, Fortier \& Leggett 1983, Sulkin 1984, Laprise \& Dodson 1989, Little \& Epifanio 1991, Olmi 1994, Rowe \& Epifanio 1994a). Whether the outcome of an active migration or simply the result of passive turbulent dispersion (see de Wolf 1974, 1981 and Boicourt 1982), a shift in the vertical position of the larvae synchronized with the tidal cycle results in differences in transport velocity between tidal phases.

Transport of larval stages towards the sea appears to occur mainly in decapod crustaceans. Portunids and oxipodids seem to be especially adapted to export their larvae early in ontogenic development. For instance, first zoea of Callinectes sapidus (McConaugha et al. 1981, Dittel \& Epifanio 1982, Provenzano et al. 1983. Epifanio et al. 1984) and of UCa spp. (Christy 1982, Lambert \& Epifanio 1982, Brookins \& Epifanio 1985, Paula 1993) are more common in surface waters during night ebbing tides. This pattern of occurrence, which is the outcome of synchronous hatching and active swimming to the surface (see Sulkin 1984 and Forward 1987 for reviews), results in a transport of the larvae to the lower parts of the estuaries and, eventually, to the sea, where they are advected under the influence of coastal circulation. Vertical movements of $U_{C a}$ spp. larvae, synchronized with the tidal cycle, were also described in estuarine waters (DeCoursey 1976). These observations suggest that selective tidal stream transport may also be used by larvae of these species, not in the classical sense of a mechanism for unidirectional upstream transport in estuaries, but rather to maximize their seaward transport.

Carcinus maenas is a portunid crab that inhabits European estuaries. Ovigerous females move to the lower parts of these systems to release their larvae. In a study conducted in the Canal de Mira (Ria de Aveiro, Portugal), Queiroga et al. (1994) showed that females release their larvae synchronously during night ebbing neap tides. Only the first and last larval stages (first zoea and megalopa, respectively) are present inside the estuary but all the larval series occurs in adjacent shelf waters (Queiroga 1996). Recently, Zeng \& Naylor (1996) demonstrated that the first zoea of Carcinus maenas migrates vertically in synchrony with the tidal cycle. During this migration, which is endogenously controlled, the larvae reach their highest position in the water column at the times of expected ebb tides These observations strongly support the hypothesis that larvae of estuarine organisms may use selective tidal stream transport to migrate towards the sea.

In this paper we analyze 2 aspects of the vertical distribution of Carcinus maenas first zoea in the Canal de Mira, in relation to the tidal and daily cycles: the mean depth of distribution of the larvae and the pattern of their vertical dispersion along the water column. We show that this stage uses selective tidal stream transport to enhance exportation from the estuary. We quantify the effect of a shift in the larvae's vertical position on their tidal transport velocity, through the calculation of a quantity that we name the instantaneous larval velocity.

\section{METHODS}

Field sampling. The sampling program described in the present study was designed to investigate several hypotheses about hatching rhythmicity, larval transport and recruitment of Carcinus maenas in Canal de Mira. The reader is referred to Queiroga et al. (1994) for details not described hereafter. Plankton samples were collected with a pump, fitted to a $500 \mu \mathrm{m}$ net, during 2

Table 1. Starting dates of the $25 \mathrm{~h}$ fixed station plankton sampling cycles performed during the winter and spring sampling periods at Stn 2

\begin{tabular}{|c|c|c|c|}
\hline $\begin{array}{l}\text { Sampling } \\
\text { period }\end{array}$ & Date & $\begin{array}{c}\text { Water current } \\
\text { data? }\end{array}$ & $\begin{array}{c}\text { Residual } \\
\text { circulation study? }\end{array}$ \\
\hline \multirow[t]{12}{*}{ Winter } & 12 Feb & Yes & - \\
\hline & 14 Feb & Yes & - \\
\hline & 16 Feb & Yes & Yes \\
\hline & 18 Feb & Yes & - \\
\hline & 20 Feb & Yes & Yes \\
\hline & $22 \mathrm{Feb}$ & Yes & - \\
\hline & 24 Feb & - & - \\
\hline & 26 Feb & Yes & Yes \\
\hline & $28 \mathrm{Feb}$ & - & - \\
\hline & $04 \mathrm{Mar}$ & Yes & Yes \\
\hline & 06 Mar & Yes & Yes \\
\hline & $11 \mathrm{Mar}$ & - & - \\
\hline \multirow[t]{9}{*}{ Spring } & 09 May & Yes & Yes \\
\hline & 11 May & Yes & Yes \\
\hline & 13 May & Yes & Yes \\
\hline & 15 May & - & - \\
\hline & $19 \mathrm{May}$ & Yes & - \\
\hline & 23 May & - & - \\
\hline & 25 May & - & - \\
\hline & $02 \mathrm{Jun}$ & - & - \\
\hline & $07 \mathrm{Jun}$ & - & - \\
\hline
\end{tabular}


sampling periods, in the Canal de Mira (Fig. 1): one in the winter and the other in the spring of 1990. Each of the 2 sampling periods was designed as a series of $25 \mathrm{~h}$ sampling cycles at a fixed station. Within each 25 h sampling cycle plankton samples were collected every hour at several depths. In the present paper we analyze only the data collected at Stn 2 (Fig. 1), for which a more complete database was obtained. Table 1 lists the dates of the fixed station studies as well as other relevant information.

In winter, the samples were collected in a quick succession over $1 \mathrm{~m}$ depth intervals within each hourly period, starting at $0.2 \mathrm{~m}$. Every time the last sample in the series was collected more than $0.5 \mathrm{~m}$ from the bottom, an extra sample was taken at $0.2 \mathrm{~m}$ from the bottom. The filtered volume at each depth was on the order of $1 \mathrm{~m}^{3}$, for a pumping time of 2 min. In spring, plankton samples were not collected at regular depth intervals but only at 3 levels: $0.5 \mathrm{~m}$ below the surface, at mid-water and $0.5 \mathrm{~m}$ above the bottom. Pumping time at each depth was increased to 5 min, corresponding to filtered volumes of ca $2.2 \mathrm{~m}^{3}$.

In both sampling periods some hydrological measurements were also obtained every hour, at the standard $1 \mathrm{~m}$ depth intervals, immediately before the collection of the plankton samples. Salinity and temperature were measured during all 25 h cycles, using a Model 33 SCT meter from Yellow Springs Instrument, USA. During some of the $25 \mathrm{~h}$ cycles current speed and direction could also be obtained (Table 1) with the use of a BMF008 current meter maufactured by Valeport, UK. The height of the water column was always measured every hour with a sounding line.

Sampling, in both sampling periods, was always started $4 \mathrm{~h}$ before the expected high water time at each sampling station. Plankton samples were preserved in $4 \%$ buffered formaldehyde immediately after collection. Carcinus maenas larvae were identified to stage level following Rice \& Ingle (1975) and counted on each whole sample.

Before we describe the methodology of analysis, it is convenient to define several terms that will be used regularly. For the sake of simplicity, all the tides cov-

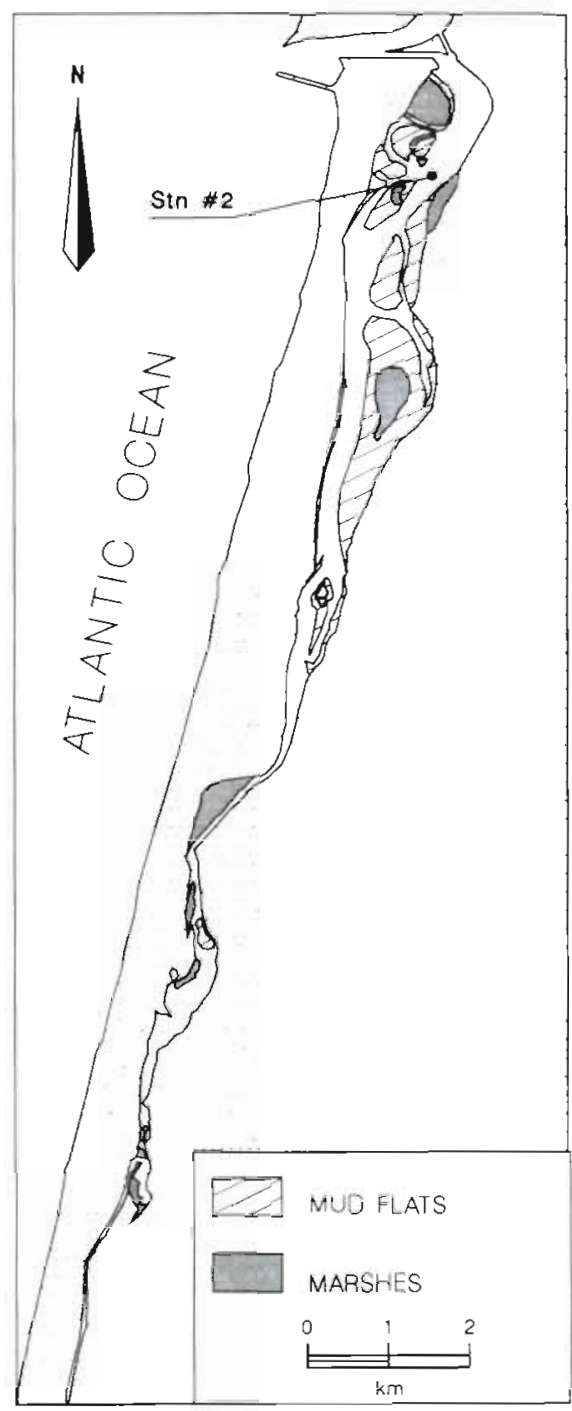

Aveiro, Portugal. Locat
fixed station studies

ered by a particular $25 \mathrm{~h}$ fixed sampling cycle will be designated by the starting date of that cycle, even when they in fact occurred on the next calendar day. The data obtained from all the sampling cycles conducted at $\operatorname{Stn} 2$ constitute the complete database. The cycles for which water current data could be obtained form the reduced database. Unless otherwise specified we always refer to the complete database. All samples collected in each sampling moment (= each period of $1 \mathrm{~h}$ ) were classified as ebb or flood samples according to the phase of the tide, defined by high and low water slack times, during which the discrete time interval began. Similarly, the samples were classified as belonging to either the day or night phases, where the day phase was taken as the period between daily sunrise and sunset and the night phase as the complement of this. Furthermore, the sampling moments within a 
tidal cycle were categorized in $1 \mathrm{~h}$ time intervals around the respective high water time: all the samples collected up to $1 \mathrm{~h}$, between $2 \mathrm{~h}$ and $3 \mathrm{~h}$, between $3 \mathrm{~h}$ and $4 \mathrm{~h}$, etc., after high water were coded $+1 h_{1}+2 \mathrm{~h}$, $+3 \mathrm{~h}$, etc; samples collected up to $1 \mathrm{~h}$, between $2 \mathrm{~h}$ and $3 \mathrm{~h}$, between $3 \mathrm{~h}$ and $4 \mathrm{~h}$, etc., before high water were coded $-1 h,-2 h,-3 h$, etc. We shall refer to the tidal cycle represented in this form as the normalised tidal cycle. Few sampling moments began more than $6 \mathrm{~h}$ before or after high water and only in 2 of these were some larvae collected. These samples were not included in the analysis.

Hydrological data analysis. The calculation of the residual circulation at Stn 2 was based on the first $13 \mathrm{~h}$ of the sampling cycles of February 16, 20 and 26. March 4 and 6 and June 9,11 and 13. This subset of data was selected because the weather and water current conditions allowed a very stable mooring of the small boat from which the observations were made. Consequently, the vertical position of the current meter and of the pump hose intake (see below) could be regulated very precisely while, at the same time, variations in water depth were only due to rising and falling of the tide and not to small lateral displacements of the boat. The calculations were made using the algebraic equivalent of the method described by Pritchard (1952), the only formal difference being the use of an average time for the reversal of the current instead of the depth-specific time of reversal. This was considered to be an acceptable approximation in view of the small average time difference between the reversal of the current at the surface and the bottom (Queiroga 1995). Ebb velocities were taken as positive velocities and flood velocities as negative. The depthspecific average current velocity in each phase of 1 tidal cycle, $\bar{u}_{\mathrm{pt}_{z}}\left(\mathrm{~m} \mathrm{~s}^{-1}\right)$, is given by:

$$
{\overline{u_{p t}}}_{z}=\frac{\sum_{t=1}^{p} u_{z t} \times \Delta T_{t}}{\sum_{t=1}^{p} \Delta T_{t}}
$$

where $u$ is the longitudinal component of velocity, pt is the phase of the tide (ebb or flood), $\Delta T$ is the time interval that corresponds to each velocity measurement, the subscripts $z$ and $t$ refer to the depth and time intervals, respectively, and $p$ is the number of time intervals in each phase. Summing the ebb (positive) and flood (negative) values, one obtains the depth-specific residual velocity in the tidal cycle. Since each $25 \mathrm{~h}$ cycle of observations was always started ca $4 \mathrm{~h}$ before high water time, the total duration of flood was considered to be identical to the duration of the next flood period, which was completely covered by the cycle of observations. The measurements taken at $0.2 \mathrm{~m}$ were excluded because they were affected by the proximity of the boat's hull.
Stratification of the water column was characterized by an index of stratification, $S$, calculated as:

$$
S=\frac{\sigma_{\text {suriace }}-\sigma_{\text {bottom }}}{Z_{t}}
$$

where $\sigma$, water density, was derived from the salinity and temperature measurements according to the equation given by Fofonoff \& Millard (1983) and $Z_{t}$ is the instantaneous depth of the water column.

Vertical distribution of the larvae. To inspect the temporal patterns of variation of the vertical position of the first zoea of Carcinus maenas we first calculated the following quantities, where $z$ and $t$ again refer to the discrete depth and time intervals. The depthspecific instantaneous concentration of the larvae, $C_{z t}$ (ind $\mathrm{m}^{-3}$ ), is:

$$
C_{z t}=\frac{\text { counts }_{z t}}{\text { filtered volume }}
$$

The instantaneous mean depth of the larvae, $\overline{D I}_{t}$ which we shall abbreviate to instantaneous depth of the larvae, was calculated as the weighted average depth of collection:

$$
\overline{D l}_{t}=\frac{\sum_{z=1}^{n} C_{z t} \times D_{z t}}{\sum_{z=1}^{n} C_{z t}} \times \frac{1}{Z_{t}}
$$

where $D$ is the depth of sampling, $Z$ is the total height of the water column, and $n$ is the number of vertical strata sampled during each sampling moment. In Eq. (4), dividing the absolute mean depth at the moment of collection by the total height of the water column transforms this quantity into an average relative depth, where the surface has a value of 0 and the bottom a value of 1 . This transformation is convenient because we can then compare positions along the vertical axis independently of the state of the tide. In order to inspect the patterns of variation of the instantaneous mean depth of the larvae we plotted the average values along normalised day and night tidal cycles. For this, we pooled the data obtained within each sampling period and averaged the instantaneous depth of the larvae for all observations made in each time interval of the normalised tidal cycle. We further investigated the overall effect of the phases of tide and day on the vertical position of the larvae through a 3-way analysis of variance (ANOVA), in which phase of tide (ebb, flood), phase of day (day, night) and sampling period (winter, spring) constituted the 3 factors in the analysis, each with 2 levels. Prior to the analysis the data were subjected to an angular transformation. This transformation homogenized the variances in all cases.

To evaluate changes in the pattern of vertical dispersion of the larvae throughout the tidal and daily cycles we calculated an index of dispersion based on Taylor's power law (Taylor 1961, Elliot 1977, Frontier 1978-1979). 
According to this law, the variance of a population $\left(\sigma^{2}\right)$ is proportional to a fractional power of the arithmetic mean $(\mu)$ :

$$
\sigma^{2}=a \mu^{b}
$$

and, therefore,

$$
\log \sigma^{2}=\log a+b \log \mu
$$

The slope of Eq. (6), b, is an index of dispersion. It varies continuously from 0 for a perfect regular distribution, through 1 for a random distribution $\left(\sigma^{2}=\mu\right)$, to infinity for a highly contagious distribution. The in stantaneous average concentration, $\bar{C}_{1}$, and variance. $s_{1}^{2}$, of the larvae are, respectively,

$$
\begin{gathered}
\bar{C}_{t}=\frac{\sum_{z=1}^{n} C_{z t}}{n} \\
s_{t}{ }^{2}=\frac{\sum_{z=1}^{n}\left(C_{z t}-\bar{C}_{t}\right)^{2}}{n-1}
\end{gathered}
$$

where $C_{z l}$ is defined by Eq. (3) and $n$ is the number of vertical strata sampled during each hourly sampling moment. Eq. (6) was fitted, by least squares regression, to the estimates $\bar{C}_{1}$ and $s_{1}{ }^{2}$ obtained for every $1 \mathrm{~h}$ time interval in which $\bar{C}_{1}$ differed from 0 . Strong heterogeneity of the residual variances between time intervals, as well as correlation of these quantities with the logarithm of the average along the regression lines. makes the use of covariance analysis to test for differences of $b$ and, thus, for vertical dispersion in the tidal and daily cycles unadvisable. Instead, we examined the biological significance of the change of the dispersion index through analysis of its pattern of variation along normalised night and day tidal cycles, for the pooled data collected within each sampling period.

Horizontal transport. To assess the influence of the vertical position of the larvae on their net tidal transport we first calculated the average instantaneous current velocity $\bar{u}_{i}\left(\mathrm{~m} \mathrm{~s}^{-1}\right)$, as the vertically integrated current velocity:

$$
\bar{u}_{l}=\frac{\sum_{z=1}^{n} u_{z t} \times \Delta D_{z t}}{\sum_{z=1}^{n} \Delta D_{z t}}
$$

where $u$ is the longitudinal component of velocity, $\Delta D$ is the height of each stratum and $\sum_{z=1}^{n} \Delta D_{z t}$ equals $Z_{t}$, the instantaneous height of the water column. Then, we calculated a vertically integrated instantaneous larval velocity, $\bar{u}_{l},\left(\mathrm{~m} \mathrm{~s}^{-1}\right)$, which we shall designate as the instantaneous larval velocity:

$$
\bar{u}_{1_{i}}=\frac{\sum_{z=1}^{n} u_{z l} \times \Delta D_{z t} \times C_{z t}}{\sum_{z=1}^{n} \Delta D_{z t} \times C_{z t}}
$$

where the different symbols have the same meanings as explained above. Note that if the larvae are uniformly distributed along the water column, the $C_{z t}$ terms in Eq. (10) are all equal and cancel out to produce a figure that is equal to $\bar{u}_{i}$ in Eq. (9). The larvae are thus transported at a velocity that equals the vertically integrated current velocity. If the $C_{z t}$ terms are not equal because the larvae do not distribute evenly with depth, then $\bar{u}_{l_{t}}$ does not equal $\bar{u}_{t}$. Since the intensity of tidal currents usually increases to the surface, as a consequence of bottom friction, an aggregation of the larvae at, e.g., the surface (bottom) results in a instantaneous transport velocity that is higher (lower) than the depth-integrated current velocity. Whichever the nature of the variation of instantaneous water velocity with depth, the difference between water velocity and larval velocity is thus a measure of the gain (or loss) in velocity that the larvae experience due to changes in vertical position. We analysed the effects of the phases of tide and day and of the sampling period on the instantaneous larval velocity by means of a 3-way ANOVA, using the instantaneous current velocity as a co-variable. The analysis was performed on the reduced database. No transformation was applied to the data because of homogeneity of variances. The concept of larval velocity described above is similar to the one reported in a previous paper by Rowe \& Epifanio (1994b). The difference is that we calculated depth-integrated larval velocity for each time interval, while Rowe \& Epifanio calculated time-integrated larval velocity for each depth interval.

Plankton samples during the spring sampling period were obtained only below the surface, at mid-depth and above the bottom, while during the winter period they were taken at $1 \mathrm{~m}$ depth intervals. In order to analyze the influence of the 2 sampling methods on the estimates of the instantaneous vertical position and velocity of the larvae, we used the first 13 sampling hours of the sampling cycles performed at Stn 2 on February 16, 20 and 26 and March 4 and 6. As stated before, these observations were selected because the depth of sampling could be determined very precisely. We first calculated, for all sampling moments, the instantaneous depth and velocity of the larvae, with Eqs. (4) \& (10), using the observations obtained at regular intervals. The same variables were again calculated from a subsample, but now using only the samples collected at $0.2 \mathrm{~m}$, at the depth level closer to half of the height of the water column and above the bottom. The 2 series of values were then compared by least squares linear regression. It was demonstrated (see below) that the 2 methods of sampling did not produce significantly different estimates of either the instantaneous vertical position or the instantaneous velocity of the larvae. 


\section{RESULTS}

\section{Hydrology}

The residual velocity profiles obtained during this study at Stn 2 are characteristic of a partıally mixed estuary (Bowden 1967, Pritchard 1967). The depth of no net motion was located at around $2.5 \mathrm{~m}$. Above this depth the net flux is downstream and is upstream below. The highest absolute residual velocity value $\left(0.06 \mathrm{~m} \mathrm{~s}^{-1}\right)$ was obtanned at $42 \mathrm{~m}$ during flood

Average current velocity and stratıficatıon values along normalised tidal cycles, for sampling moments when first zoea were collected, are shown in Fig 2. To facilitate comparison with other figures the results are given separately for observations made during night and day. No clear differences in water velocity were found between phases of the tide at Stn 2, but spring values were consistently higher than those found in winter. The water column was clearly stratified during winter, responding to the larger volume of discharged freshwater. Stratification was much lower an spring

\section{Vertical distribution}

The average concentration of the first zoea was more than 4 times higher in spring than in winter (3.3 ind. $\mathrm{m}^{-3}$ against 0.7 ind. $\mathrm{m}^{-3}$, respectively; Queiroga et al 1994) This stage was usually distributed closer to the surface during ebb, particularly when this phase of the tıde councided with the night, as can be seen from, e.g , the data included in the reduced database (Fig. 3). The difference in the sampling methodology used to collect the larvae in the 2 sampling periods did not affect the calculation of the vertical position. There was a highly significant linear relation $(\mathrm{p} \ll$ 0001 ) between the estimates of the relative depth based on sampling at surface, mid-water and bottom $\left(R D_{\mathrm{SM} B \mathrm{~B}}\right)$ and at regular intervals $\left(R D_{\mathrm{R} l}\right)$. Moreover, the slope of the regression line and the $Y$-intercept $\left(R D_{\mathrm{SMB}}=1.047 R D_{\mathrm{Rl}}-0.0148\right)$ did not differ from 1 and 0 , respectively ( $\mathrm{p}>0.50$ in both cases; Student's $t$-test).

The pooled data within the sampling periods of winter and spring (Fig. 4) show a clear shift of the vertical position of the first zoea synchronized with the tidal cycle. The zoeae reached their highest position in the water column during ebb and their lowest during flood. The average amplitude of the vertical movements spanned over ca $6 / 10$ of the water column and the range of the movements of individual larvae most certainly reached even higher values. The extent and phasing of vertıcal dısplacements were such that the first zoea occupied a significantly lower position during the span of the flood than during the ebb $(p<0.001)$. It could also be demonstrated that the larvae were closer to the surface during the night $(\mathrm{p}<0.05)$ and in winter $(\mathrm{p}<0.01)$. None of the interactions between the factors were statistically significant at the $5 \%$ level, although the phase of tide versus phase of day interaction was close to signuficance $(0.10>p>0.05 ; p>0.25$ for the other interactions). Scatter diagrams of instantaneous relative depth against instantaneous current velocity show that the larvae tend to concentrate in the higher half of the water column during ebb (higher density of data points above 0.6 relative depth) and in the lower half during flood (higher density of data points below 0.4 relative depth) (Fig. 5A) The instantaneous depth of the larvae did not show any meaningful relationship with the stratification index (Fig, 5B, C). Namely, the higher

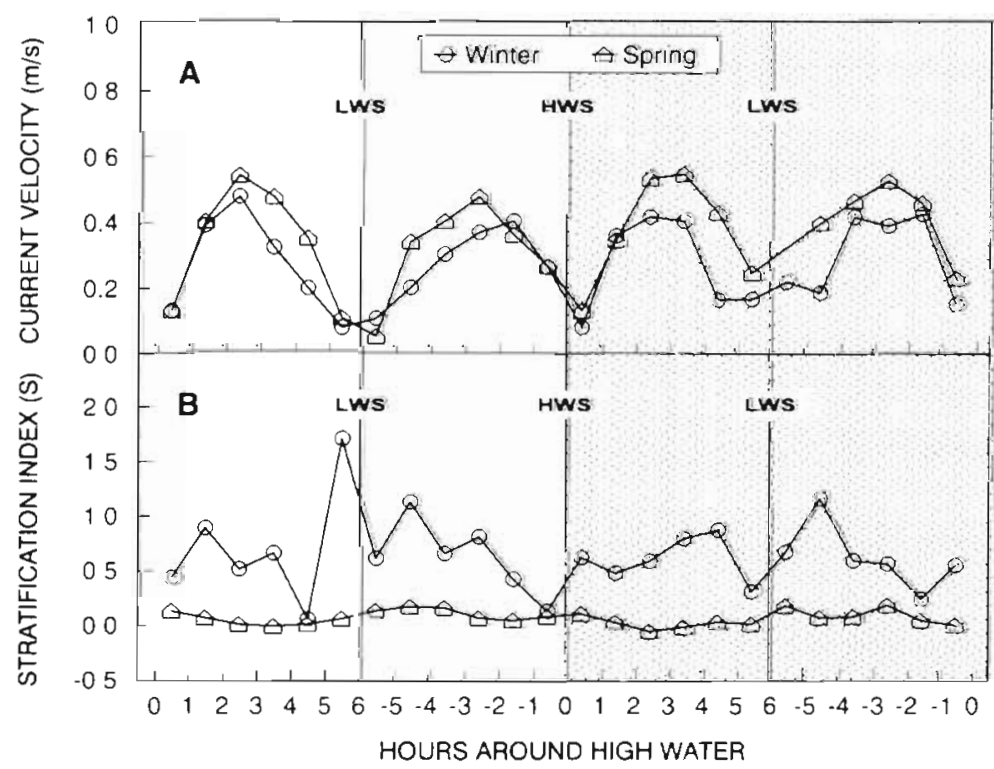

Fig 2 (A) Longitudinal current velocity average values and (B) average stratification index for normalised day and night tidal cycles, for the pooled data collected within each sampling perıod. Only the sampling moments when first zoed were collected are included. Panel A only includes data from the reduced database. HWS: high water slack; LWS: low water slack; dotted area: night 


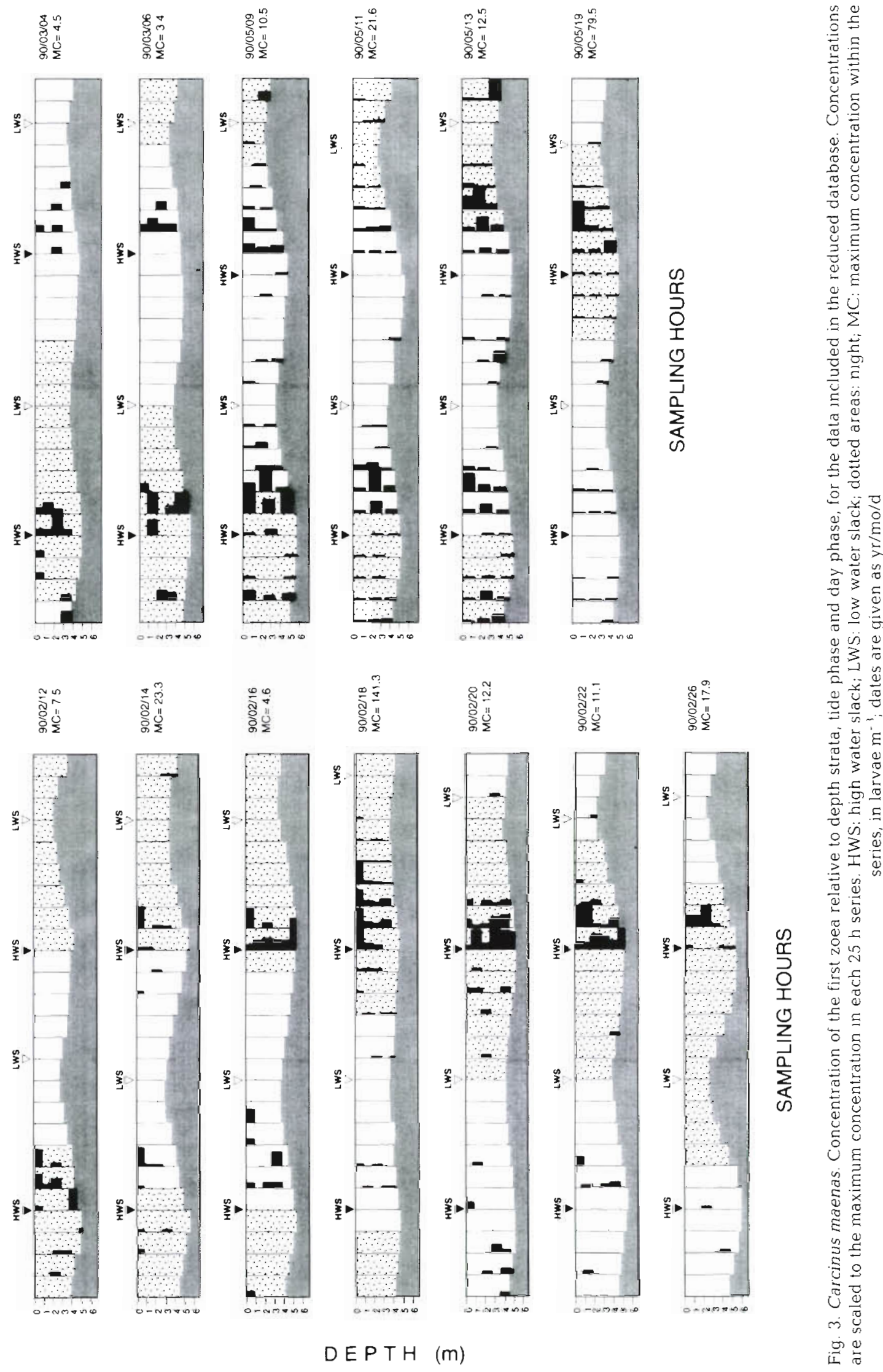




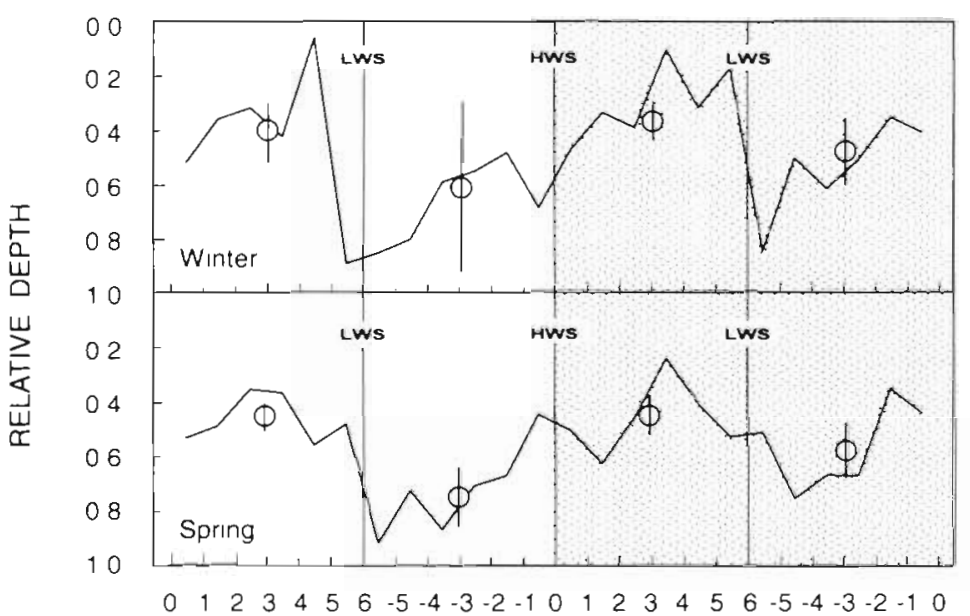

Fig 4 Carcinus maenas. Effects of phase of tide and phase of day on the vertical position of the first zoea, for the pooled data collected within each sampling period. Circles represent average position during full half cycles. Vertical bars represent $95 \%$ confidence intervals. HWS: high water slack; LWS low water slack; dotted area: night

HOURS AROUND HIGH WATER

density stratification of the water observed during winter did not seem to affect the instantaneous depth of the larvae.

The pattern of vertical dispersion of the larvae appeared to change cyclically with a perıod equivalent to the tidal half cycle, independently of season (Fig. 6). Maximum aggregation usually occurred 2 to $3 \mathrm{~h}$ after high or low water slack tımes. when current velocity is higher Around slack the first zoeae were randomly or unıtormly distributed along the water column, as indıcated by dispersion index values about or below 1 No apparent relation exists between aggregation of the larvae and phases of the tide or day. Comparison of Figs. 6 \& 2 shows that the degree of aggregation does not depend on water stratıfication, because the range of variation of the dispersion index was the same in the 2 sampling perıods, albeit a much higher stratıfıcation of the water in winter

\section{Horizontal tidal transport}

There was a highly significant linear relatıon $(\mathrm{p} \ll$ $0.001)$ between the estimates of the instantaneous lar- val velocity obtanned by sampling at surface, midwater and bottom $\left(L V_{S M B}\right)$ and at regular intervals $\left(L V_{\mathrm{RI}}\right)$, with slope and $Y$-intercept $\left(L V_{\mathrm{SMB}}=1.013 L V_{\mathrm{R} I}\right.$ - 0.003) that were not significantly different from 1 and 0 , respectively ( $\mathrm{p}>0.20$ in both cases; $t$-test). As for the calculation of the instantaneous depth of the larvae, the results seem not to be affected by the different level of resolution used to sample the water column.

Table 2 shows the average values of the difference between the instantaneous larval velocity and the instantaneous current velocity for each sampling period. Results of the ANOVA of the effects of phases of tide and day and of sampling period show that, as expected, the effect of the co-variable instantaneous current velocity is highly significant ( $p \ll 0.001$ ). This obviously means that larval velocity is related to current velocity The results also show that all main factors affect significantly the velocity of the first zoea (phase of tide: $p<0.001$; phase of day: $p<0.05$; sampling period: $p<0.01$ ). The interactions were not significant, with the exception of the phase of day versus sampling period interaction $(p<0.05)$. Change of the vertical position of the zoeae thus results in different transport

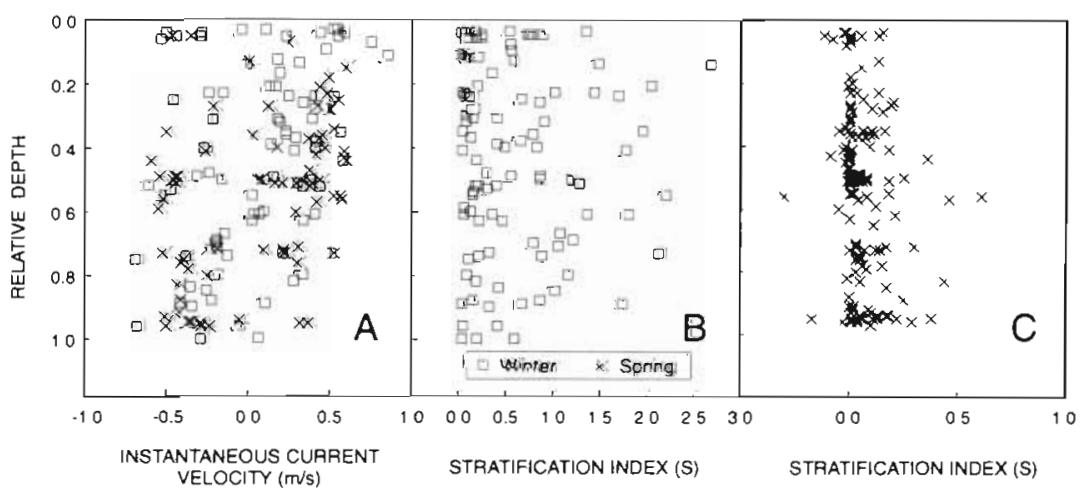

Fig 5. Carcinus maenas. Scatter plots of the instantaneous relative depth of the furst zoea against (A) instantaneous current velocity in winter and spring fonly data from the reduced database), (B) instantaneous stratification index in winter and $(C)$ instantaneous stratification index in spring 


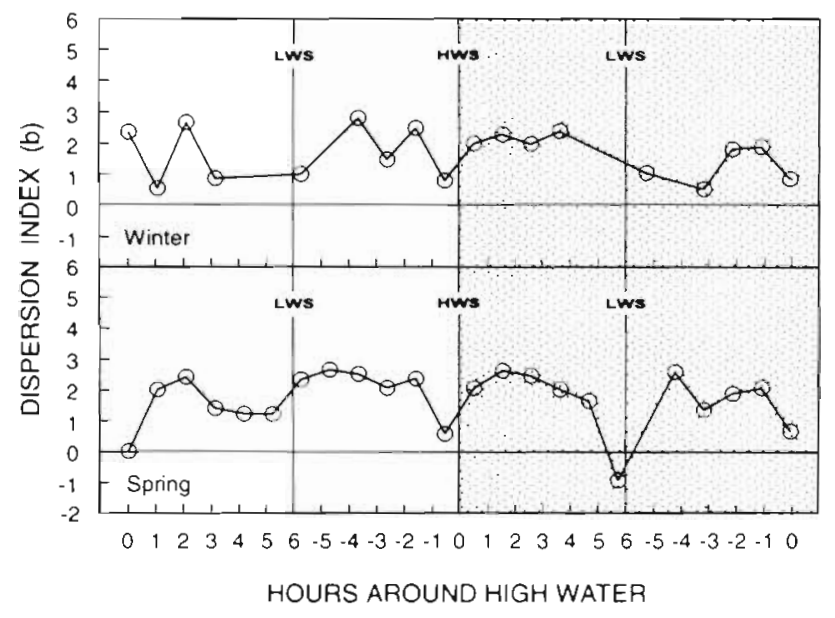

Fig. 6. Carcinus maenas. Effects of phase of tide and phase of day on the vertical dispersion index of the first zoea. for the pooled data collected within each sampling period Each dispersion index value represents the slope of the regression line of $\log s_{1}{ }^{2}$ on $\log \bar{C}_{1}$ for observations made in time intervals of $1 \mathrm{~h}$ before (negative hours) and after (positive hours) high water. HWS: high water slack; LWS: low water slack; dotted area: night

velocities, according to phase of thde, phase of day and season. During ebb, the average velocity of the larvae is consistently higher than the current velocity and is lower during flood. For instance, average larval velocity during ebb is ca $8 \%$ higher than current velocity, while it is lower by a similar proportion $(9 \%)$ durıng flood. When decomposed by sampling period, larval velocity during ebb can exceed current velocity by about $15 \%$ and, during flood, it can be lower by about $27 \%$. These reported differences between larval and water velocity arise only from the vertical distribution of the zoea We cannot exclude that the zoeae are also swimming horizontally, in which case the resultant effect would have to be added to the velocity of the larvae as we defined it. However, there are no records of directional, steady, horizontal swimming of crab zoeae in the hterature

\section{DISCUSSION}

When interpreting the observed patterns of vertical distribution of the larvae, it must be realized that the observations were made on a fixed point and, therefore, different water masses and different larvae were sampled with tıme. Moreover, the pooled data for each sampling penod are average values, obtamed tor identical time intervals in the tidal cycle but from observations made on different days. The patterns observed in this study thus represent the average situation. Larval trajectories along the vertical axis of the estuary during each individual darly cycle do certannly deviate from the average pattern. Nevertheless, it is clear that Carcmus maenas first zoea was significantly closer to the surface by night and during the ebb.

It has been argued that differences in current velocity between the 2 phases of the tide that are common in many estuares as a consequence of the tidal wave asymmetry would, by themselves, result in different average vertical positions of the larvae and other planktonic organisms between phases of the tide. Resuspension by turbulent diffusion dunng periods of higher current velocity would be the mecha-

Table 2. Average instantaneous velocity of the furst zoea of Carcinus maenas and average instantaneous current velocity for the data included in the reduced database Positive velocity values indicate ebb velocities, negative values indicate flood Positive differences indicate that instantaneous larval velocity is higher than instantaneous current velocity

\begin{tabular}{|c|c|c|c|c|c|}
\hline $\begin{array}{l}\text { Source of } \\
\text { variation }\end{array}$ & $\mathrm{n}$ & $\begin{array}{l}\text { Average instantaneous } \\
\text { velocity of Zoea I ( } \mathrm{m} \mathrm{s}^{1} \text { ) }\end{array}$ & $\begin{array}{l}\text { Average instantaneous } \\
\text { current velocity (ms i) }\end{array}$ & $\begin{array}{c}\text { Averaged } \\
\text { difference }\left(\mathrm{m} s{ }^{\prime}\right)\end{array}$ & $\begin{array}{c}\text { Averaged } \\
\text { difference }(\%)\end{array}$ \\
\hline Ebb & 95 & 0355 & 0330 & 0025 & 757 \\
\hline Day & 44 & 0373 & 0356 & 0018 & 517 \\
\hline Winter & 16 & 0364 & 0322 & 0.047 & 14.59 \\
\hline Spring & 28 & 0378 & 0376 & 0002 & 055 \\
\hline Night & 51 & 0.339 & 0308 & 0031 & 997 \\
\hline Winter & 34 & 0.322 & 0288 & 0034 & 1168 \\
\hline Spring & 17 & 0374 & 0349 & 0.025 & 714 \\
\hline Flood & 67 & -0323 & -0354 & -0031 & -884 \\
\hline Day & 23 & -0302 & -0369 & -0067 & -1827 \\
\hline Winter & 10 & -0333 & -0.352 & -0019 & -538 \\
\hline Spring & 13 & -0.278 & -0383 & -0.105 & -2736 \\
\hline Night & 44 & -0334 & -0347 & -0.012 & -3.59 \\
\hline Winter & 25 & -0.302 & -0310 & -0.008 & -2.50 \\
\hline Spring & 19 & -0.376 & -0395 & -0019 & -472 \\
\hline
\end{tabular}


nism accounting for such differences. It has further been contended that even when larvae undergo active vertical migration in laboratory experiments this does not mean that they may do so in the field, because of the effect of strong currents and turbulent diffusion (de Wolf 1974, 1981). Various aspects of the data collected during this study, however, suggest that this is not the case. Female Carcinus maenas hatch their larvae in the deeper part of Canal de Mira (Queiroga 1995). Because crab larvae are negatively buoyant (Sulkin 1984), dispersion on the vertical axis only by turbulent diffusion could not concentrate them close to the surface during ebb, as the case often was (see Fig. 3). Changes of the average vertical position occurred with a tidal periodicity. However, the pattern of vertical dispersion changed with a semi-tidal period: during slack the larvae were overdispersed in the water column while they were concentrated during periods with high current velocity. No differences in the degree of aggregation were found between ebb and flood. If vertical displacements resulted only from passive turbulent dispersion, one would expect that both the average vertical position of the larvae and the pattern of vertical dispersion, would vary with the same period. Furthermore, if larvae behaved like passive particles, increased turbulence originated by currents of higher intensity would tend to disrupt larval aggregations, and not to concentrate the larvae as was the case. These observations suggest, therefore, that the first zoea of $C$. maenas actively migrates vertically in the Canal de Mira, in synchrony with the tidal and daily cycles. The results agree with those obtained in the laboratory by Zeng \& Naylor (1996), who showed that Carcinus maenas first zoeae, freshly collected from coastal waters, migrate vertically in synchrony with the tidal cycle, the ascent occurring during expected ebb tides and the descent during expected flood. The rhythm persisted, in constant conditions, for a span of time equivalent to several tide cycles and was thus under endogenous control.

The amplitude of the observed migrations was such that the average position of the first zoea resulted in instantaneous larval velocities that were higher than the instantaneous current velocity during ebb. On the contrary, during flood the first zoea was transported at a velocity that was lower than the current velocity. These effects were further modulated by the depth change associated with the phase of the day. This behaviour resulted in a quick transport of the larvae to the sea. Those larvae that did not reach the sea before the turn of the tide minimized their upstream transport by assuming a lower position in the water column. The average gain in velocity during ebbs may reach $15 \%$ of the current velocity, corresponding to a difference of
$0.047 \mathrm{~m} \mathrm{~s}^{-1}$. This implies that the distance travelled by an average first zoea during the span of the ebb may exceed that of an average particle of water by $1100 \mathrm{~m}$, that is, more than $1 / 4$ of the distance that separates Stn 2 from the inlet of Ria de Aveiro.

Selective tidal stream transport has been proposed to explain the upstream movement of fish and invertebrate larvae against the net seaward flux of estuarine waters. This is the mechanism that prevents the export of the larvae of Rhithropanopeus harrisii (Cronin \& Forward 1979, 1983, 1986. Forward \& Cronin 1980, Cronin 1982) and that helps the reinvasion of the estuary by megalopae of Callinectes sapidus (Little \& Epifanio 1991, Olmi 1994), Uca spp. (Christy 1982, Little \& Epifanio 1991) and Carcinus maenas (Queiroga 1995). The present study shows that selective tidal stream transport can be generalized as an unidirectional transport mechanism in estuaries, which cannot only promote upstream transport of planktonic organisms but may also enhance exportation to the sea.

Vertical distribution and transport of larvae of fish and benthic invertebrates in stratified estuaries has been interpreted in terms of variation of the vertical position as a function of the level of no net motion. When the larval stages are retained inside the estuary, as in the crab Rhithropanopeus harrisii or the fishes Osmerus mordax (Laprise \& Dodson 1989) and Clupea harengus harengus (Fortier \& Leggett 1983), the larvae remain above the level of no net motion during flood and below during ebb. In the case of Carcinus maenas, the phasing of the vertical displacements is such that the larvae are above the depth of no net motion during ebb and below during flood. However, for a vertically migrating larva, the residual circulation may not be relevant to its transport. The extreme points reached during the migration at Stn 2 are at about $8 / 10$ of the total depth during flood and $2 / 10$ during ebb. For an average depth at the sampling station of $4.7 \mathrm{~m}$ this corresponds to 3.8 and $1.0 \mathrm{~m}$ respectively. At $3.8 \mathrm{~m}$ the residual upstream flux is close to the maximum (Queiroga 1995), and yet the larvae are transported at an average velocity that is lower than the current velocity. The important factor is not the residual velocity to which, in fact, the larvae are never subjected, but rather the instantaneous velocities to which they expose themselves in the course of the vertical migration. At $3.8 \mathrm{~m}$ the instantaneous flood velocities observed during this study were lower than the velocities at $1.0 \mathrm{~m}$ during ebb. This difference is the factor that controls the net downstream transport. Residual circulation is certainly important when vertical tidal migrations are not involved. In contrast, a vertically migrating larva has the ability to 'control' its velocity, becoming independent of the residual vertical structure of the estuary. 
Acknowledgements. The authors thank Mr Fernando Morgado (Departamento de Biologia, Universidade de Aveiro) and the many students of the Departamento de Biologia who made possible the successful accomplishment of the field work. Several fascinating discussions with Dr Ramiro Neves (Instituto Superior Técnico) on estuarine hydrology were also important for the final form of the manuscript. This study received financial support from Junta Nacional de Investigaçào Científica e Tecnológica (Project no. 87/122), and was conducted while one of us (H.Q.) was the holder of a scholarship granted by the Instituto Nacional de Investigação Científica.

\section{LITERATURE CITED}

Boehlert GW, Mundy BC (1988) Roles of behavioural and physical factors in larval and juvenile recruitment to estuarine nursery areas. Am Fish Soc Symp 3:51-67

Boicourt WC (1982) Estuarine larval retention mechanisms on two scales. In: Kennedy VS (ed) Estuarine comparisons. Academic Press, New York, p 445-457

Bowden KF (1967) Circulation and diffusion. In: Lauff GH (ed) Estuaries. American Association for the Advancement of Science, Publication No. 83, Washington, DC, p 15-36

Brookins KG, Epifanio CE (1985) Abundance of brachyuran larvae in a small coastal inlet over six consecutive tidal cycles. Estuaries 8:60-67

Chia FS, Buckland-Nicks J, Young CM (1984) Locomotion of marine invertebrate larvae: a review. Can J Zool 62: $1205-1222$

Christy JH (1982) Adaptive significance of semilunar cycles of larval release in fiddler crabs (Genus Uca): test of an hypothesis. Biol Bull (Woods Hole) 163:251-263

Cronin TW (1982) Estuarine retention of larvae of the crab Rhithropanopeus harrisii. Estuar Coast Shelf Sci 15: $207-220$

Cronin TW, Forward RB Jr (1979) Tidal vertical migration: an endogenous rhythm in estuarine crab larvae. Science 205:1020-1022

Cronin TW, Forward RB Jr (1983) Vertical migration rhythms of newly hatched larvae of the estuarine crab Rhithropanopeus harrisii. Biol Bull (Woods Holel 165:139-153

Cronin TW, Forward RB J (1986) Vertical migration cycles of crab larvae and their role in larval dispersal. Bull Mar Sci 39:192-201

DeCoursey PJ (1976) Vertical migration of larval UCa in a shallow estuary. Am Zool 16:244

de Wolf P (1974) On the retention of marine larvae in estuaries. Thalassia Jugosl 10:415-424

de Wolf $P(1981)$ Is retention the result of active or passive phenomena? Estuaries 4:239

Dittel AI, Epifanio CE (1982) Seasonal abundance and vertical distribution of crab larvae in Delaware Bay. Estuaries 5:197-202

Elliot JM (1977) Some methods for the statistical analysis of samples of benthic invertebrates. Freshwater Biological Association Scientific Publication No. 25, Titus Wilson \& Son Kendal

Epifanio CE (1988) Transport of crab larvae between estuaries and the coastal shelf. In: Jansson BO (ed) Coastal-offshore ecosystems interactions. Lecture notes on coastal and estuarine studies, Vol 22. Springer-Verlag, Berlin, $p$ $291-305$

Epifanio CE, Valenti CC, Pembroke AE (1984) Dispersal and recruitment of blue crab larvae in Delaware Bay USA Estuar Coast Shelf Sci 18:1-12

Fofonoff NP, Millard RC Jr (1983) Algorithms for computation of fundamental properties of seawater. UNESCO Technical Papers in Marine Sciences No. 44, Paris

Fortier L, Leggett WC (1983) Vertical migrations and trans port of larval fish in a partially mixed estuary. Can J Fish Aquat Sci 40:1543-1555

Forward RB Jr (1987) Larval release rhythms of decapod crustaceans: an overview. Bull Mar Sci 41:165-176

Forward RBJr, Cronin TW (1980) Tidal rhythms of activity and phototaxis of an estuarine crab larvae. Biol Bull (Woods Hole) 158:295-303

Frontier S (1978-1979) La microrépartition du plankton étude statistique, implications méthodologiques, perspectives de recherche. Vie Milieu 28-29(2, AB):189-208

Lambert R, Epifanio CE (1982) A comparison of dispersal strategies in two genera of brachyuran crab in a secondary estuary. Estuaries 5:182-188

Laprise R, Dodson JJ (1989) Ontogeny and importance of tidal vertical migrations in the retention of larval smelt Osmerus mordax in a well-mixed estuary. Mar Ecol Prog Ser 55:101-111

Little KT, Epifanio CE (1991) Mechanism for the reinvasion of an estuary by two species of brachyuran megalopae. Mar Ecol Prog Ser 68:235-242

McConaugha JR, Provenzano AJ, Johson DF, Clark J, Sadler $P$ (1981) Offshore displacement and reinvasion of Callinectes sapidus larvae in Chesapeake Bay. Estuaries 4:277

Mileikovsky SA (1973) Speed of active movement of polagic larvae of marine bottom invertebrates and their ability to regulate their vertical position. Mar Biol 23:11-17

Miller J (1988) Physical processes and mechanisms of coastal migrations of immature marine fishes. Am Fish Soc Symp $3: 68-76$

Olmi EJIII (1994) Vertical migration of blue crab Callinectes sapidus megalopae: implications for transport in estuaries. Mar Ecol Prog Ser 113:39-54

Paula J (1993) Ecologia da fase larvar e recrutamento de crustáceos decápodes no estuário do Rio Mira. Tese de Doutoramento, Universidade de Lisboa, Lisboa

Pritchard DW (1952) Salinity distribution and circulation in the Chesapeake Bay estuarine system. J Mar Res 11 106-123

Pritchard DW (1967) Observations of circulation in coastal plain estuaries. In: Lauff $\mathrm{GH}$ (ed) Estuaries. American Association for the Advancement of Science, Publication No. 83, Washington, DC, p 37-44

Provenzano AJ Jr, McConaugha JR, Philips KB, Johnson DF, Clark J (1983) Vertical distribution of first stage larvae of the blue crab, Callinectes sapidus, at the mouth of the Chesapeake Bay. Estuar Coast Shelf Sci 16:489-499

Queiroga H (1995) Processos de dispersāo e recrutamento das larvas do caranguejo Carcinus maenas na Ria de Aveiro. Tese de Doutoramento, Universidade de Aveiro, Aveiro

Queiroga H (1996) Shelf distribution and drift of the crab Carcinus maenas (L.) (Decapoda, Portunidae) larvae off northern Portugal in April of $1991 \mathrm{~J}$ Plankton Res 18: $1981-2000$

Queiroga H, Costlow JD Jr, Moreira MH (1994) Larval abundance patterns of Carcinus maenas (Decapoda, Brachyura) in Canal de Mira (Ria de Aveiro, Portugal). Mar Ecol Prog Ser 111:63-72

Rice AL, Ingle RW (1975) The larval development of Carcinus maenas (L.) and Carcinus mediterraneus Czerniavsky (Crustacea, Brachyura, Portunidae) reared in the laboratory. Bull Br Mus (Nat Hist) Zool 28:103-119 
Rowe PM, Epifanio CE (1994a) Tidal stream transport of weakfish larvae in Delaware Bay, USA. Mar Ecol Prog Ser 110:105-114

Rowe PM, Epifanio CE (1994b) Flux and transport of larval weakfish in Delaware Bay, USA. Mar Ecol Prog Ser 110: $115-120$

Sulkin SD (1984) Behavioral basis of depth regulation in the

This article was submitted to the editor larvae of brachyuran crabs. Mar Ecol Prog Ser 15:181-205 Taylor LR (1961) Aggregation, variance and the mean. Nature 189:732-735

Zeng C, Naylor E (1996) Endogenous tidal rhythms of vertical migration in field collected zoea-1 larvae of the shore crab Carcinus maenas: implications for ebb tide offshore dispersal. Mar Ecol Prog Ser 132:71-82

Manuscript first received: July 15, 1996

Revised version accepted: December 23, 1996 